\title{
The effects of pre-harvest and post-harvest factors on the nutritional quality of strawberry fruits: A review
}

\author{
Josè M. Alvarez-Suarez ${ }^{\mathrm{a}, \mathrm{b}}$, Luca Mazzoni ${ }^{\mathrm{b}}$, Tamara Y. Forbes-Hernandez ${ }^{\mathrm{b}}$, Massimiliano Gasparrini ${ }^{\mathrm{b}}$, \\ Silvia Sabbadini ${ }^{\mathrm{a}}$ and Francesca Giampieri ${ }^{\mathrm{a}, *}$ \\ ${ }^{a}$ Dipartimento di Scienze Agrarie, Alimentari e Ambientali (D3A), Università Politecnica delle Marche, \\ Ancona, Italy \\ ${ }^{\mathrm{b}}$ Dipartimento di Science Cliniche Specialistiche ed Odontostomatologiche (DISCO), Sez. Biochimica, \\ Facoltà di Medicina, Università Politecnica delle Marche, Ancona, Italy
}

Received 9 February 2014; accepted 10 February 2014

\begin{abstract}
In the last years, the nutritional quality of fruits has been widely evaluated and requested by consumers, mainly because of the health effects they provide. As known, these benefits can be due to micronutrients, as vitamins and minerals, but also to phenolic compounds, as flavonoids and ellagitannins. In this context, strawberries represent a very good choice for a diet low in saturated fats and sodium and, at the same time they are rich in fiber, potassium and other minerals, vitamins, and antioxidant phytochemicals: all elements that are currently considered as the essential constituents of a well-balanced diet. However, the nutritional quality of strawberry fruits can be considerably affected by several pre-harvest and post-harvest conditions, which, in most cases, may decrease the nutrient and the phytochemical contents of this fruit.

This paper reviews and updates the current knowledge on the nutritional and phytochemical composition of strawberry, paying particular attention on the role played by the genotype, the maturity, the environment, the storage and the processing on the nutritional quality of this fruit.
\end{abstract}

Keywords: Strawberry, nutritional quality, phenolic compounds, antioxidant capacity, maturity, genotype, environment, storage, processing

\section{Introduction}

The nutritional quality (NQ) of fruit is a very complex parameter, since it is still very hard to identify the attributes which could give a comprehensive idea of the "healthy power" of a fruit. Certainly, the fruit content of specific micronutrients (minerals, vitamins) is a clear NQ indicator, whereas the situation is much more complicated when evaluating the content of non essential compounds, like polyphenols.

Strawberry (Fragaria $\times$ ananassa) has a relevant NQ, due to its high levels of micronutients as vitamin C, folate and minerals as well as of phenolic constituents [1-4], that have shown huge biological potentialities in humans [5-8].

*Corresponding author: Dr. Francesca Giampieri, PhD, D3A, Università Politecnica delle Marche, Italy, Via Ranieri 65, 60100 Ancona, Italy. Tel.: +39 071 2204136; Fax: +39 071 2204123; E-mail: f.giampieri@univpm.it. 
This fruit is of economic and commercial relevant importance and largely consumed both in fresh or in processed form, such as jams, juices, and jellies, making it the most studied berry from an agronomic, genomic and nutritional point of view.

Micronutrients and phenolic compound concentrations in strawberry are known to be affected by many preharvest conditions, as genotype and maturity at harvest, and postharvest factors, as storage period and temperature, and processing $[9,10]$. For example, several significant changes in nutrient and phytochemical composition are related with the genotype, that determines the quantity and the quality of fruits, but also with the ripening, because many chemical and compositional modifications occur when the fruit is still attached to the mother plant. On the other side, the delay between harvest and storage at the appropriate temperature is known to be critical for the success of the treatment, while the use of low temperature and of modified atmospheres is essential to avoid least partially mould growth and fruit senescence, and thus extending strawberry shelf-life.

The aim of this work is to discuss the nutrient and photochemical composition of strawberry, with specific focus on the most significant compounds and the effects that several pre- and post-harvest factors may exert on the NQ of this fruit.

\section{Compostion}

\subsection{Nutrients}

According to their nutrient composition, strawberries are a very healthy fruit. Firstly, they are low in total calories, with a $100 \mathrm{~g}$ serving providing only $32 \mathrm{kcal}$; then, their sweet flavor make them a delicious wholesome snack alternative to processed foods, as their dietary fiber $(2.4 \mathrm{~g} / 100 \mathrm{~g})$ and fructose $(>50 \%$ total sugars) contents both regulate blood sugar levels by slowing digestion, and contribute to a satiating effect [4]. The extremely high content of vitamin $\mathrm{C}$ (Fig. 1) in strawberry (even higher than citrus fruit) is one of the aspects of major nutritional relevance. The vitamin $\mathrm{C}$ content of strawberry fruits results to vary between 0.1 and $1 \mathrm{mg} \mathrm{g}^{-1} \mathrm{FW}$ (fresh fruit) for several strawberry genotypes, while its content in flesh is about $58.8 \mathrm{mg} / 100 \mathrm{~g} \mathrm{FW}[4,10,11]$. Thus, the vitamin $\mathrm{C}$ content in strawberry is a crucial factor affecting NQ of the fruit, and its variation is an important parameter when comparing both commercial varieties and new selections.

Folate (Fig. 1) is a micronutrient that strengthens the NQ of strawberry being in the range of $20-25 \mu \mathrm{g} / 100 \mathrm{~g}$ (FW), much higher than in other fruits [4]. However, there are still few studies focused on the evaluation of the folate content of fresh strawberries [11, 12], of its stability during storage, as well as of its retention after fruit processing.

Because of the lower content of other vitamins in strawberry, the main interest is currently focused on the determination of vitamin $\mathrm{C}$ and folate in the fruits, for their potential impact on human health. However, strawberry, even if in a lower extent, is a sufficiently good source of several other vitamins, such as thiamin (B1), riboflavin (B2), niacin (B3), vitamin B6, vitamin K, vitamin A and vitamin E [4]. Strawberry contains also many minerals, as manganese, potassium, iodine, magnesium, copper, iron and phosphorus [4].

\subsection{Phytochemical compounds}

In addition to traditional nutrients, strawberries are among the richest dietary sources of phytochemicals. In the strictest sense, phytochemicals can be defined as secondary metabolites produced by plants; however, the term is generally used to describe chemicals from plants that may affect health, but are not designated as traditional nutrients. In the last decades, with the advent of highly sensitive analytical methods, knowledge on the composition of strawberry fruits has rapidly expanded, allowing to obtain the phytochemical profiles or "chemical fingerprint" of these fruits. They serve many diverse biological functions including roles in plant growth, development, and defense: for example, they provide pigmentation, antimicrobial and antifungal functions, insect-feeding deterrence, UV radiation protection, chelation of toxic heavy metals, antioxidant quenching of free radicals generated during photosynthesis, and much more. There are four main classes of strawberry phenolic compounds: flavonoids (mainly anthocyanins, with flavonols, and flavanols giving a minor contribution), hydrolyzable tannins (ellagitannins and gallotannins), phenolic acids (hydroxybenzoic acids and hydroxycinnamic acids) and condensed tannins (proanthocyanidins). Structural diversity 
<smiles>O=C1O[C@H]([C@H](O)CO)C(O)=C1O</smiles>

Vitamin C<smiles>O=C(Oc1cc2c(O)cc(O)cc2cc1O)[C@H]1O[C@H](CO)[C@@H](O)[C@H](O)[C@H]1O</smiles>

Pelargonidin-3-glucoside<smiles>O=C1Oc2c(O)c(=O)oc3c(O)c(O)cc1c23</smiles>

Ellagic acid<smiles>Nc1nc2ncc(CNc3ccc(C(=O)N[C@@H](CCC(=O)O)C(=O)O)cc3)nc2c(=O)[nH]1</smiles>

Folate<smiles>O=C(O)C1O[C@H](Oc2c(-c3ccc(O)c(O)c3)oc3cc(O)cc(O)c3c2=O)[C@H](O)[C@H](O)[C@H]1O</smiles>

Quercetin-3-glucoronide

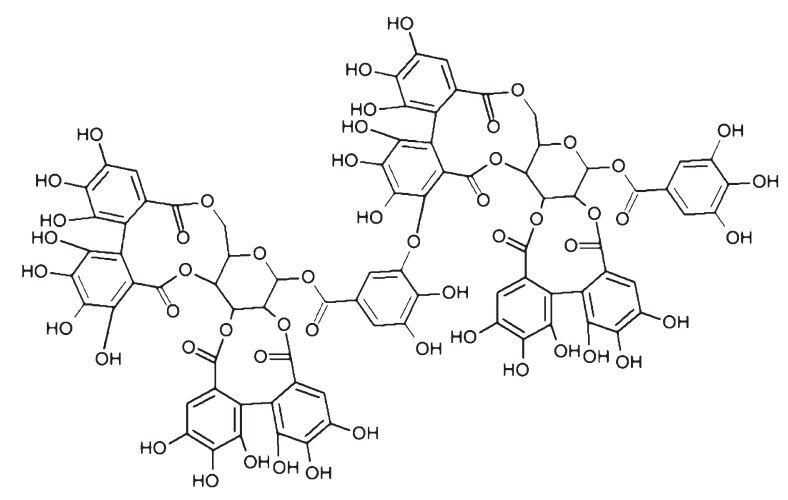

Sanguiin H-6

Fig. 1. Chemical structures of the most common compounds present in strawberry.

within these phenolics is dependent on types and oxidation levels of their heterocyclic ring(s), their substitution patterns of hydroxylation, their glycosylation by various sugars and/or acylation by organic and phenolic acids, and by conjugation to form polymers. 


\subsubsection{Anthocyanins}

Anthocyanins are the glycosylated form of anthocyanidins, which are polyhydroxyl and polymethoxy derivatives of 2-phenylbenzopyrylium or flavylium salt. They contain two benzoyl rings (A and B) separated by a heterocyclic (C) ring. The deglycosylated or aglycone forms of anthocyanins are known as anthocyanidins. The six most common forms of anthocyanidins are cyaniding $(\mathrm{Cy})$, delphinidin, pelargonidin $(\mathrm{Pg})$, malvidin, petunidin, and peonidin, with a distribution in nature of 50,12,12,12,7, and 7\%, respectively [13]. They represent the most relevant water-soluble pigments in plant, and flavonoid subclass which probably deserves the most attention, since the daily uptake of anthocyanins in human diet is remarkable and much higher than the total intake estimated for other flavonoids.

Pg 3-glucoside is the major anthocyanin in strawberry (Fig. 1) [14-16], but, even if in smaller amount, also Cy 3-glucoside seems also to be constant in all varieties [17-19], as well as Pg 3-rutinoside, which are commonly found in strawberry fruits $[4,20]$. Moreover, other anthocyanins have been found in some strawberry cultivars as Pg 3-arabinoside [21] and Cy 3-rutinoside [17]. These findings are in agree with those obtained in a recent study that confirmed similar anthocyanin compositions in nine Italian cultivars [22].

Various acylated anthocyanins with a range of aliphatic acids have been reported in several strawberry cultivars, too. In particular Pg 3-(6-malonylglucoside) has been indicated as one of the main pigments in several Japanese cultivars, comprising $5-30 \%$ of total anthocyanin content $[23,24]$. Other acylated anthocyanins also found in strawberry are Pg 3-acetylglucoside and Pg succinylglucoside [14, 15].

\subsubsection{Ellagitannins}

Ellagitannins (ETs) are together with anthocyanins the most abundant phenolic compounds in strawberry [25, 26]. They are hydrolyzable tannins, with a wide range of structures such as monomers (ie, ellagic acid glycosides) (Fig. 1), oligomers (ie, dimers sanguiin H-6) (Fig. 1), and complex polymers. Even if ETs have been identified as the active principles in medicinal plants [27], they are quite unusual in foodstuffs. Recently, Koponen et al. [28] studied 33 commonly consumed foods in Finland and screened them for ellagitannin content. Ellagic acid compounds were detected only in five foods, all berries from the family Rosaceae (cloudberry, raspberry, rose hip, and strawberry), that contained high levels of ellagic acid equivalents. In this study the ellagitannin contents, expressed as ellagic acid equivalents, ranged between from 21.7 to $83.2 \mathrm{mg} / 100 \mathrm{~g}(\mathrm{FW})$, while free ellagic acid derivaties ranged between 0.7 and $4.3 \mathrm{mg} / 100 \mathrm{~g}(\mathrm{FW})$. The authors reported that ellagic acid was mostly presented as ellagitannins, and the relative amount of free ellagic acid and its glycosides (non-tannin ellagic acid) was $<6 \%$, and in most cases only $1-2 \%$. Other previous study reported the ellagitannin contents of strawberry were between $25-59 \mathrm{mg} / 100 \mathrm{~g}$ in fresh samples [29-31].

Despite of the above considerations, a few studies have identified and quantified the ellagitannin compounds themselves. Recently, Aaby et al. [31] and Seeram et al. [32] reported an important group of oligomeric ellagitannins in strawberry (Fragaria $\times$ ananassa): galloylbis-hexahydroxydiphenoyl (HHDP)-glucose, previously reported in Rubus berry [4]. This molecule is a basic unit of many ETs, for example, sanguiin H-6 and lambertianin C contain 2 and 3 units, respectively [4]. However, in this field more studies are desirable, especially because of their important impact on human health.

\subsubsection{Other phenolics}

Strawberry is also a moderate source of other polyphenolic compounds. Many studies focused on strawberry flavonol content and composition [4,33]. Similarly to anthocyanins, flavonols occur naturally in glycosilated forms, where the associated sugar moiety is very often glucose or rhamnose, although other substituents such as glucuronic acid, galactose, arabinose and xylose may also be involved. The flavonols identified in strawberries are derivatives of quercetin and kaempferol, being quercetin-3-glucuronide (Fig. 1) the most abundant. Also acylated flavonols such as quercetin- and kaempferol-3-malonylglucoside, and kaempferol-coumaroylglucoside have been found in some strawberry cultivars [31]. The interest on the flavonol composition in strawberry is recently arisen since convincing evidence suggests that these molecules appear in human plasma and urine in far higher concentrations than anthocyanins [4]. Additionally, mechanisms of passive and active transport of quercetin aglycones and glucosides through the epithelia of the gastrointestinal tract have been extensively studied in human [34] and animal models $[35,36]$, and the potential bioefficacies of the bioavailable metabolites are under investigation. 
Flavanols are the only subclass of phenols that do not occur naturally as glycosilated forms. In strawberry they have been found in both monomeric (catechins) and polymeric forms called condensed tannins or procyanidins (PCs), especially in strawberry flesh and achenes [26]. They have shown to possess directly and indirectly antioxidant, antimicrobial, anti-allergy, anti-hypertensive, and inhibition of the activities of some physiological enzymes and receptors properties [37].

Finally, a variety of phenolic acids are present in strawberry as derivatives of hydroxycinnamic acid (HCA, i.e. caffeic acid) and hydroxybenzoic acid (HBA, i.e. gallic acid) [4]. Soluble HCA derivaties are more common than the HBA ones, consist chiefly of $p$-coumaric, caffeic and ferulic acids [29, 31] and are generally found as glycoside and as esters with sugars or quinic acids (such as $p$-coumaroylhexose, $p$-coumaroylhexose-4-O-hexoside, or ferulic acid hexose derivatives). Unlike HCA, HBA derivatives are mostly found in the form of glucosides, even if glucose esters are occasionally observed.

\section{Antioxidant capacity}

In past decades, strong attention has been given to the antioxidant power of fruit as an eligible parameter for quality and as indicator of the presence of beneficial bioactive compounds in foodstuffs and, therefore, of their healthfulness. This parameter is strictly associated to the concentration of efficient radical scavengers, such as vitamin C and phenolic compounds. In this context, strawberries possess greater antioxidant capacity (2- to 11-fold) than apples, peaches, pears, grapes, tomatoes, oranges, or kiwifruit [2], with vitamin $\mathrm{C}$ responsible, per se, for more than $30 \%$ of the TAC followed by the anthocyanins contributing between $25-40 \%$ (depending on the cultivar) and the rest attributed to the contribution of mainly comprised ellagic acid derivatives and flavonols [22]. These findings may support previous studies, confirming that associations between the antioxidant properties and the proportion of phenolics present as anthocyanins or ETs are generally not very evident in strawberry [25, 38-43].

\section{Factors affecting the NQ of strawberry}

\subsection{Maturity}

The polyphenol composition of strawberry changes through growth and stage of ripening: generally unripe fruit pulp have higher levels of phenolic compounds than ripe fruit pulp. While the strawberry are green, the total content of phenolics and flavonoids are high, and they decrease over the ripening period. In a recent study [44] four cultivars from three different ripening stages (full size green fruits, pink fruits and ripe red fruits) were compared and was found that green strawberries of all genotype had a higher content of phenolic compounds than pink and red one. These results are in keeping with other studies, which reported that green strawberry fruits of different varieties had the highest level of phenolics compound and flavonoids than pink or red fruits and that these contents decreased during maturity [45-47]. In contrast, the levels of vitamin C can increase in the dark red berries, but this increase is not always statistically significant, depending on genotype, storage effects or environmental factors [48, 49].

Also anthocyanin profile varies during maturity, but with an opposite trend: in all cultivars anthocyanins are stored in red stage, coinciding with a red-color fruits, whereas small amounts are present in pink fruits and they are absent in green fruits $[9,46,47]$.

Finally, the antioxidant capacity varies during ripening period with the same trend of the phenolic compounds; according to many studies, the TAC of the fruits gradually decrease during maturity and this reduction is strictly associated with a strong decrease of tannins, while polar non-phenolic antioxidants, such as vitamin C, only slightly increase upon ripening, without affecting the decreasing trend [9, 47, 49].

\subsection{Genetic and environmental factors}

Phenol concentrations and TAC in foods vary according to many genetic, environmental, and technological factors, some of which may be controlled to optimize the NQ of fruits and vegetable [35]. In particular, the genetic background 
plays an important role on the NQ of strawberry fruits, since the content of micronutrients and phytochemicals may greatly vary from cultivar to cultivar. However, few genotypes have been well characterised for these important features, and still limited knowledge is available on the possibility of improving strawberry nutritional traits by breeding. On the other hand, growing conditions, such as type of soil, exposure to sunlight and humidity level, can also influence the micronutrient and phytochemical content of strawberry fruits, thus affecting their nutritional value. Regarding the total phenolic content, there are large differences among cultivars and among cultural systems. In a study Tulipani et al. [23] compared four different genotypes of strawberry and found a 1,8-fold difference between the highest and lowest value of total phenolic content. In particular, cultivar Adria had the lowest value $(2.11 \mathrm{mg}$ GAE/g FW), while Sveva had the highest (2.83 mg GAE/g FW). Other values were found by Wang et al. [47], who reported that the individual concentration of total phenolic in the extract of eight strawberry cultivars ranged between 95 and $152 \mathrm{mg} / 100 \mathrm{~g}$ (FW), while Capocasa et al. [50] and Skupien et al. [30] reported a concentration that ranged from 1.80 to $3.20 \mathrm{mg} \mathrm{GAE} / \mathrm{g}$ (FW) and from 3.17 to $4.43 \mathrm{mg} \mathrm{GAE} / 1 \mathrm{~g}$, respectively. Finally, Scalzo et al. [3] analyzed six cultivated varieties and one wild strawberry, observing important differences among cultivars, with a range of concentration between $1093 \mathrm{mg}$ GAE/L (cv Idea) and $2128 \mathrm{mg}$ GAE/L (cv Patty).

The anthocyanin profile and levels can vary by several factors, too. Lopes da Silva et al. [15] reported a notable variability among several samples of different variety and year: the individual concentrations of the three major anthocyanins (i.e. Cy 3-glucoside, Pg 3-glucoside, Pg 3-rutinoside) in the extracts of five strawberry varieties ranged between 200 to $600 \mathrm{mg} / \mathrm{kg}$ (FW). Other values of total anthocyanins were reported by Clifford [13], between $150-350 \mathrm{mg} / \mathrm{kg}$, while Meyers et al. [51], in a study carried out with eight different strawberry varieties, reported average concentrations of $414 \mathrm{mg} / \mathrm{kg}$, with strong differences among cultivars. Moreover, Garcia-Viguera et al. [52] reported concentrations from 185 to $840 \mathrm{mg} / \mathrm{kg}$ in samples of Oso Grande and Camarosa, respectively. It is interesting to note that anthocyanin content in Camarosa strawberries determined by Castro et al. [53] (482 mg/kg, FW) was closer to those reported by Lopes da Silva et al. [15] (468 mg/kg, FW). On the other hand, Tulipani et al. [54] indicated concentrations between $99-296 \mathrm{mg} / \mathrm{kg}$ (FW) in nine Italian strawberry cultivars.

As evidenced, phenolic compounds and anthocyanin concentrations may strongly differ, even within the same variety, depending of the degree of ripeness, the climatic factors and post-harvest storage, and these characteristics are necessary when assessing these parameters as possible indicators of the NQ of fruit. It should also be taken into account that differences in concentration found for a same variety by different authors might also be due to the use of different extraction techniques.

Since the TAC parameter is closely related to the presence of vitamin $\mathrm{C}$ and phenolic compounds, there is a considerable variability in TAC values among strawberry cultivars. Scalzo et al. [3] have exposed a positive proof that the interaction of these different factors can determine the antioxidant capacity of a specific fruit and should be take into account to better characterize agronomic production and information to the consumer. In this study, the authors showed that the TAC is strongly influenced by species or cultivar: the wild species $F$. vesca had the highest TEAC values, which were 2.5-fold higher than the average of the most common cultivated Italian strawberry varieties. These results are in agreement with other studies, that found remarkable differences in antioxidant capacities between different cultivars of strawberry fruits [23, 47, 49].

All these studies suggest that, when a comparison is made among data in the literature, the varieties should be known and considered and, because genetic modifications produce differently enriched fruits, the possibility of different manipulations (by means of traditional breeding or advanced biotechnology or genetic manipulation) [55, 56] could be a powerful tool for modifying antioxidant fruit patterns and contents [2, 3, 22, 47].

Finally, also the environmental conditions in which plants grow and climate changes that take place each year during the strawberry ripening period may partly explain the large difference in the content of micronutrients and phytochemicals. When assessing the content of polyphenols and TAC of strawberry fruits, different cultural practices need to be taken into account. Wang and Millner [42] reported that fruits from plants grown in compost socks had significantly higher phenolic content, flavonoid, anthocyanin and oxygen radical absorbance capacity rather than those grown in a matted row system. Moreover, these authors found also that vinegar treatment in culture practice showed significant effect, generally increasing total phenolic, total anthocyanin and TAC values. These results are in agreement with other studies, showing a lowest content of micronutrient and antioxidant capacity in fruits of plants grown in the matter row system than that grown in the hill plasticulture system [57]. 
Furthermore, Jin et al. [58] compared two different varieties cultivated both in organic and inorganic cultivation, finding that strawberries grown from organic culture exhibited generally higher activities in antioxidant enzymes and contained significantly higher level of phytonutrients than those produced from conventional culture. On the contrary, a study carried out by Hakkinen et al. [33] showed that organic cultivation had no consistent effects on the level of phenolic compounds in strawberry. These authors analyzed three different varieties and found similar levels of flavonols and phenolic acids when these different cultivation techniques were used, except for the cultivar Jonsok, which had a $12 \%$ higher concentration of total phenolics if cultivated with organic system. However, this difference was due to the higher contents of ellagic acid and kaempferol in strawberry cultivated by the organic technique than in those cultivated by the conventionally system. Unfortunately, there are still few studies on the effect of cultural system on nutritional value of strawberry, so that further analysis should be performed.

\subsection{Storage and processing effects}

Short-term storage strongly influences NQ and micronutrient and phytochemical profiles of strawberry, and storage temperature seems to be one of the key factors particularly affecting the stability of phenolic antioxidants in fruits, during postharvest storage. Many authors have studied how phenolic composition, anthocyanin, and TAC in berry may change during storage treatments [49, 54, 59-61]. Our group [54] also found that the most evident effect of storage (storage for two days at $4^{\circ} \mathrm{C}$ one day at room temperature, in the dark) in the cultivars investigated was in folate content, since the levels of folate increased in all the genotype studied. Unfortunately, this investigation remains one of the very few studies currently available on the effect of the storage on folate, whereas further evidence are needed.

With regard to the NQ, the total phenolic and anthocyanin content are not affected by storage, as well as vitamin C; on the contrary, the flavonoid concentration is significantly higher in fruits after short-term storage [49, 54, 59-61]. These results could be due to the fact that during storage an increase in the content of early-eluting polar phenolic antioxidants occur. The total phenolic compounds and anthocyanin of strawberry fruits may increase if temperature and storage time are extended. Kalt et al. [41] stored strawberry at $0^{\circ}, 10^{\circ}, 20^{\circ}$, and $30^{\circ} \mathrm{C}$ for up to 8 days. The most considerable increase in phytochemical composition was recorded for anthocyanin: in fact, its content increased an average of 4,3-fold after 8 days, and the magnitude of increase was related to temperature. When strawberry were stored at $0^{\circ} \mathrm{C}$ for 8 days, anthocyanins increased 1,7 -fold, while for the same period at $30^{\circ} \mathrm{C}$, the apparent increase was 6,8-fold. Other authors obtained similar results: they stored strawberry at $0^{\circ}, 5^{\circ}, 10^{\circ} \mathrm{C}$ for up to 7 days and found that berries stored at $10^{\circ} \mathrm{C}$ had higher level of total phenolics and total anthocyanins content than those stored at $0^{\circ}$ or $5^{\circ} \mathrm{C}[58,62]$. This result could be ascribed to the postharvest phenolic metabolism of fruits and anthocyanin would have be formed from a pool of precursors with a small overall effect on antioxidant capacity.

Short-term storage positively affects also the antioxidant capacity of strawberry fruits, since the complex reactions taking place within the fruits during postharvest period may facilitate formation of compounds with enhanced antioxidant capacity, even when fruit attributes, such as taste and smell, have already significantly deteriorated [61]. Generally, during storage TAC can increase [54] or remain stable [60,61], and the higher is the exposure time and temperature of storage the greater is the increase in antioxidant capacity [58, 62].

In conclusion, storage temperature $>0^{\circ} \mathrm{C}$, especially during prolonged periods, seems to positively affect phenolic metabolism in strawberry, thus enhancing, in most cases, phenolic content and TAC, but more studies are necessary to better define these features.

Strawberries are generally consumed as fresh fruits, even if many products such as juice, nectar, puree, jam and jellies are available on the market. The fruit juice redilution or concentration, the storage in tank farm, the production of strawberry jam by heating under vacuum, bottling, closing under vacuum and cooling are the main processes for strawberry derived products [63]. Several studies showed that strawberry products possess a decreased NQ compared to fresh fruits, and that the degree of reduction is strictly related to production time and processing steps, such as heat treatment. For example, Hartmann et al. [64] studied the influence of different processing steps on quality parameters of strawberry and found that thawing, mashing and especially pasteurization showed a negative effect on vitamin C, total phenolic content, and anthocyanins, while TAC was only slightly affected. This is probably due to the formation of new antioxidant compounds, such as the products of the Maillard reaction that occur during heating. The authors reported that to reach the maximal yield of polyphenols, anthocyanins, and TAC, a short enzymatic treatment is 
favorable. Klopoteck et al. [63] processed strawberry fruits to juice, nectar, wine and puree, finding a decrease in all investigated parameters (total phenolic content, anthocyanin, vitamin C and TAC) within processing berry to the different products. Only puree, produced with a few processing steps without pasteurization, showed the best quality of the measured compounds. Finally, Bursac Kovacevic et al. [65] reported that during processing fruit into jams, phenolic compounds decreased in all jam samples by $45-63 \%$, flavonoid by $10-36 \%$ and nonflavonoid by $7-40 \%$, while in a study by Hakkinnen et al. [66] the loss was about $15-20 \%$ for flavonoid and $20 \%$ for total ellagic content. In conclusion, processed strawberry may be an excellent source of food ingredient especially only if compositional changes associated with processing are minimised, so that each processing step should be executed efficiently, and long holding times should be avoided to restrict oxidation processes.

\section{Conclusions}

Strawberries contain a variety of beneficial compounds, including minerals, vitamins, fatty acids, and dietary fiber, as well as a wide range of polyphenolic phytochemicals (flavonoids, phenolic acids, hydrolysable and condensed tannins). As evidenced, strawberry nutrient and phenolic concentrations may vary according to many pre- and postharvest factors, depending of the genotype, the degree of ripeness, the climatic factors and post-harvest storage: these characteristics are necessary when considering these parameters as possible indicators of the NQ of fruit. These considerations are also essential for both agronomic production and for fruit industry, on one side to improve strawberry genotypes in term of nutrient and phytochemical compounds and, and on the other side, to avoid processing steps and product treatments that lead to a high reduction of the NQ.

\section{References}

[1] Battino M, Beekwilder J, Denoyes-Rothan B, Laimer M, McDougall GJ, Mezzetti B. Bioactive compounds in berries relevant to human health. Nutr Rev. 2009;67(Suppl 1):S145-50.

[2] Scalzo J, Mezzetti B, Battino M. Total antioxidant evaluation: Critical steps for assaying berry antioxidant features. BioFactors. 2005;23:22127.

[3] Scalzo J, Politi A, Pellegrini N, Mezzetti B, Battino M. Plant genotype affects total antioxidant capacity and phenolic contents in fruit. Nutrition. 2005;21:207-13.

[4] Giampieri F, Tulipani S, Alvarez-Suarez JM, Quiles JL, Mezzetti B, Battino M. The strawberry: Composition, nutritional quality, and impact on human health. Nutrition. 2012;28:9-19.

[5] Alvarez-Suarez JM, Dekanski D, Ristic S, Radonjic NV, Petronijevic ND, Giampieri F, et al. Strawberry polyphenols attenuate ethanol induced gastric lesions in rats by activation of antioxidant enzymes and attenuation of MDA increase. PLoS One. 2011;6(10):e25878.

[6] Alvarez-Suarez JM, Giampieri F, Tulipani T, Casoli T, Di Stefano G, González-Paramás AM, et al. One-month strawberry-rich anthocyanin supplementation ameliorates cardiovascular risk, oxidative stress markers and platelet activation in humans. J Nutr Biochem. 2013. doi: 10.1016/j.jnutbio.2013.11.002

[7] Giampieri F, Alvarez-Suarez JM, Tulipani S, Gonzales-Paramas AM, Santos-Buelga C, Bompadre S, et al. Photoprotective potential of strawberry (fragaria $x$ ananassa) extract against UV-A irradiation damage on human fibroblasts. J Agric Food Chem. 2012;60:2322-27.

[8] Tulipani S, Armeni T, Giampieri F, Alvarez-Suarez JM, González-Paramás A M, Santos-Buelga C, et al. Strawberry intake increases blood fluid, erythrocyte and mononuclear cell defenses against oxidative challenge. Food Chem. 2104. doi: http://dx.doi.org/10.1016/j.foodchem.2014.01.098

[9] Cordenunsi BR, Oliveira Do Nascimento JR, Genovese MI, Lajolo FM. Influence of cultivar on quality parameters and chemical composition of strawberry fruits grown in brazil. J Agric Food Chem. 2002;50:2581-86.

[10] Kafkas E, Koşar M, Paydaş S, Kafkas S, Başer KHC. Quality characteristics of strawberry genotypes at different maturation stages. Food Chem. 2007;100:1229-36.

[11] Holasová M, Fiedlerová V, Roubal P, Pechačová M. Possibility of increasing natural folate content in fermented milk products by fermentation and fruit component addition. Czech J Food Sci. 2005;23:196-201.

[12] Tulipani S, Romandini S, Alvarez Suarez JM, Capocasa F, Mezzetti B, Busco F, et al. Folate content in different strawberry genotypes and folate status in healthy subjects after strawberry consumption. Biofactors. 2008;34:47-55.

[13] Clifford MN. Anthocyaninsdnature, occurrence and dietary burden. J Sci Food Agric. 2000;80:1063-72.

[14] Lopes-da-Silva F, de Pascual-Teresa S, Rivas-Gonzalo JC, Santuos-Buelga C. Identification of anthocyanin pigments in strawberry (cv. Camarosa) by LC using DAD and ESI-MS detection. Eur Food Res Technol. 2002;214:248-53. 
[15] Lopes-da-Silva F, Escribano-Bailòn MT, Pérez Alonso JJ, Rivas-Gonzalo JC, Santos-Buelga C. Anthocyanin pigments in strawberry. LWT. 2007;40:374-82.

[16] Bridle P, Garcia-Viguera C. Analysis of anthocyanins in strawberries and elderberries. A comparison of capillary zone electrophoresis and HPCL. Food Chem. 1997;59:299-304.

[17] Hong V, Wrolstad RE. Characterization of anthocyanin containing colorants in fruits juices by HPLC-photodiode array detection. J Agric Food Chem. 1990;38:708-15.

[18] Lukton A, Chichester CO, MacKiney G. Characterization of a second pigment in strawberries. Nature 1955;176:790.

[19] Hong V, Wrolstad RE. Use of HPLC separation/photodiode array detection for characterization of anthocyanins. J Agric Food Chem. 1990;38:708-15.

[20] Fiorini M. Preparative high-performance liquid chromatography for the purification of natural anthocyanins. J Chromatogr A. 1995;692:2139.

[21] Goiffon JP, Mouly PP, Gaydou EM. Anthocyanic pigment determination in red fruit juices, concentrated juices and syrups using liquid chromatography. Anal Chem Acta 1999;382:39-50.

[22] Tulipani S, Mezzetti B, Capocasa F, Bompadre S, Beekwilder J, Ric De Vos CH, et al. Antioxidants, phenolic compounds, and nutritional quality of different strawberry genotypes. J Agric Food Chem. 2008;56:696-704.

[23] Tamura H, Takada M, Yoshida Y. Pelargonidin 3-O-(6-Omalonyl-b-D-glucopyranoside) in Fragaria x ananassa Duch cv Nyoho. Biosci, Biotechnol Biochem. 1995;59:1157-58.

[24] Yoshida Y, Koyama N, Tamura H. Color and anthocyanin composition of strawberry fruit: Changes during fruit development and differences among cultivars, with special reference to the occurrence of pelargonidin 3-malonylglucoside. J Jpn Soc Hortic Sci. 2002;71:355-61.

[25] Kähkönen MP, Hopia AI, Heinonen M. Berry phenolics and their antioxidant activity. J Agric Food Chem. 2001;49:4076-82.

[26] Aaby K, Skrede G, Wrolstad RE. Phenolic composition and antioxidant activities in flesh and achenes of strawberries (Fragaria ananassa). J Agric Food Chem. 2005;53:4032-40.

[27] Quideau S. Chemistry and biology of ellagitannins: An underestimated class of bioactive plant polyphenols. Singapore: World Scientific, 2009.

[28] Koponen JM, Happonen AM, Törrönen AR. Contents of anthocyanins and ellagitannins in selected foods consumed in Finland. J Agric Food Chem. 2007;55:1612-19.

[29] Mattila P, Kumpulainen J. Determination of free and total phenolic acids in plant-derived foods by HPLC with diode-array detection. J Agric Food Chem. 2002;50:3660-67.

[30] Skupien K, Oszmianski J. Comparison of six cultivars of strawberries (Fragaria ananassa Duch.) grown in northwest Poland. Eur Food Res Technol. 2004;219:66-70.

[31] Aaby K, Ekeberg D, Skrede G. Characterization of phenolic compounds in strawberry (Fragaria ananassa) fruits by different HPLC detectors and contribution of individual compounds to total antioxidant capacity. J Agric Food Chem. 2007;55:4395-406.

[32] Seeram NP, Henning SM, Zhang Y, Suchard M, Li Z, Heber D. Pomegranate juice ellagitannin metabolites are present in human plasma and some persist in urine up to 48 hours. J Nutr. 2006;136:2481-85.

[33] Hakkinen SH, Torronen AR. Content of flavonols and selected phenolic acids in strawberries and Vaccinium species: Influence of cultivar, cultivation site and technique. Food Res Int. 2000;33:517-24.

[34] Manach C, Scalbert A, Morand C, Remesy C, Jimenez L. Polyphenols: Food sources and bioavailability. Am J Clin Nutr. 2004;79:727-47.

[35] Gee JM, DuPont MS, Day AJ, Plumb GW, Williamson G, Johnson IT. Intestinal transport of quercetin glycosides in rats involves both deglycosylation and interaction with the hexose transport pathway. Nutr Metab. 2000;130:2765-71.

[36] Sesink AL, Arts I, Faassen-Peters M, Hollman PC. Intestinal uptake of quercetin-3-glucoside in rats involves hydrolysis by lactase phloridzin hydrolase. J Nutr. 2003;133:773-76.

[37] Santos-Buelga C, Scalbert A. Proanthocyanidins and tanninlike compounds - nature, occurrence, dietary intake and effects on nutrition and health. J Sci Food Agric. 2000;80:1094-117.

[38] Gonzalez EM, De Ancos B, Cano MP. Relation between bioactive compounds and free radical-scavenging capacity in berry fruits during frozen storage. J Sci Food Agric. 2003;83:722-26.

[39] Deighton N, Brennan R, Finn C, Davies HV. Antioxidant properties of domesticated and wild Rubus species. J Sci Food Agric. 2000;80:130713.

[40] Prior RL, Cao G, Martin A, Sofic E, McEwen J, O’Brien C, et al. Antioxidant capacity as influenced by total phenolic and anthocyanin content, maturuty, and variety of Vaccinium species. J Agric Food Chem. 1998;46:2686-93.

[41] Kalt W, Forney CF, Martin A, Prior RL. Antioxidant capacity, vitamin C, phenolics, and anthocyanins after fresh storage of small fruits. J Agric Food Chem. 1999; 47:4638-44.

[42] Wang SY, Millner P. Effect of different cultural system on antioxidant capacity, phenolic content, and fruit quality of strawberries (Fragaria X ananassa Duch.). J Agric Food Chem. 2009;57:9651-57.

[43] Wang H, Cao G, Prior RL. Oxygen radical absorbing capacity of anthocyanins. J Agric Food Chem. 1997;45:304-9.

[44] Tulipani S, Marzaban G, Herndl A, Laimer M, Mezzetti B, Battino M. Influence of environmental and genetic factors on health-related compounds in strawberry. Food Chem. 2011;124:906-13. 
[45] Bordonaba JG, Chope GA, Terry LA. Maximising blackcurrant anthocyanins: Temporal changes during ripening and storage in different genotypes. J Berry Res. 2010;1:73-80.

[46] Kosar M, Kafkas E, Paydas S, Baser K. Phenolic composition of strawberry genotypes at different maturation stages. J Agric Food Chem. 2004;52:1586-89.

[47] Wang SY, Lin HS. Antioxidant activity in fruits and leaves of blackberry, raspberry, and strawberry varies with cultivar and developmental stage. J Agric Food Chem. 2000;48:140-46.

[48] Gil MI, Holcroft D, Kander AA. Changes in strawberry anthocyanins and other polyphenols in response to carbon dioxide treatments. J Agric Food Chem. 1997;45:62-1667.

[49] Olsson ME, Ekvall J, Gustavsson KE, Nilsson J, Pillai D, Sjo-Holm I, et al. Antioxidants, low molecular weight carbohydrates, and total antioxidant capacity in strawberries (Fragaria ananassa): Effects of cultivar, ripening, and storage. J Agric Food Chem 2004;52:2490-98.

[50] Capocasa F, Scalzo J, Mezzetti B, Battino M. Combining quality and antioxidant attributes in the strawberry: The role of genotype. Food Chem. 2008;111:872-878.

[51] Meyers KJ, Watkins CB, Pritts MP, Hai-Liu R. Antioxidant and antiproliferative activities of strawberries. J Agric Food Chem. 2003;51:688792.

[52] Garcia-Viguera C, Zafrilla P, Tomas-Barberan FT. The use of acetone as an extraction solvent for anthocyanins from strawberry fruits. Phytochem Anal. 1998;9:274-77.

[53] Castro I, Goncalves O, Teixeira JA, Vicente AA. Comparative study of Selva and Camarosa strawberries from the commercial market. J Food Sci. 2002;67:2132-37.

[54] Tulipani S, Romandini S, Battino M, Bompadre S, Capocasa F, Mezzetti B. Variation in strawberry micronutrients, phytochemical and antioxidant profiles: The combined effect of genotype and storage. ISHS Acta Horticulturae 842: VI International Strawberry Symposium, 2008 .

[55] Diamanti J, Capocasa F, Battino M, Mezzetti B. Evaluation of F. x ananassa intra-specific and inter-specific back-crosses to generate new genetic material with increased fruit nutritional quality. J Berry Res. 2010;1:103-14.

[56] Diamanti J, Capocasa F, Balducci F, Battino M, Hancock J, Mezzetti B. Increasing strawberry fruit sensorial and nutritional quality using wild and cultivated germplasm. PLoS One. 2010;7(10):e46470.

[57] Wang SY, Zheng W, Galletta GJ. Cultural system affects fruit quality and antioxidant capacity in strawberries. J Agric Food Chem. 2002;50:6534-42.

[58] Jin P, Wang SY, Wang CY, Zheng Y. Effect of cultural system and storage temperature on antioxidant capacity and phenolic compounds in strawberries. Food Chem. 2011;124(1):262-70

[59] Gil MI, Aguayo E, Kader AA. Quality changes and nutrient retention in fresh-cut versus whole fruits during storage. J Agric Food Chem. 2006;54:4284-96.

[60] Kevers C, Falkowski M, Tabart J, Defraigne JO, Dommes J, Pincemail J. Evolution of antioxidant capacity during storage of selected fruits and vegetables. J Agric Food Chem. 2007;55:8596-03.

[61] Piljac-Žegarac J, Šamec D. Antioxidant stability of small fruits in postharvest storage at room and refrigerator temperatures. Food Res Int. 2011;44:345-50.

[62] Ayala-Zavala JF, Wang SY, Wang CY, Gustavo A, González-Aguilar GA. Effect of storage temperatures on antioxidant capacity and aroma compounds in strawberry fruit. LWT - Food Sci Technol. 2004;37:687-95.

[63] Klopotek Y, Otto K, Bohm V. Processing strawberries to different products alters contents of vitamin c, total phenolics, total anthocyanins, and antioxidant capacity. J Agric Food Chem. 2005;53:5640-46.

[64] Hartmann A, Patz CD, Andlauer W, Dietrich H, Ludwig M. Influence of processing on quality parameters of strawberry. J Agric Food Chem. 2008;56:9484-89.

[65] Bursac Kovacevic D, Levay B, Dragovic-Uzelac V. Free radical scavenging activity and phenolic content in strawberry fruit and jam. Agric Conspec Sci. 2009;74:155-59.

[66] Hakkinnen SH, Karenlampi SO, Mykkanen HM, Torronen AR. Influence of domestic processing and storage on flavonol contents in berries. J Agric Food Chem. 2000;48:2960-65. 